\begin{tabular}{l|l}
$\begin{array}{l}\text { Postprint } \\
\text { Version }\end{array}$ & 1.0 \\
\hline Journal website & http://jco.ascopubs.org/content/early/2013/08/12/JCO.2012.45.5865.long \\
\hline Pubmed link & $\underline{\text { http://www.ncbi.nlm.nih.gov/pubmed/23940230 }}$ \\
\hline DOI & $10.1200 / J C O .2012 .45 .5865$
\end{tabular}

This is a NIVEL certified Post Print, more info at http://www.nivel.eu

\title{
Explicit Prognostic Information and Reassurance About Nonabandonment When Entering Palliative Breast Cancer Care: Findings From a Scripted Video-Vignette Study
}

Liesbeth M. VAn Vliet, Elsken Van Der Wall, Nicole M. Plum, AND Jozien M. BENSING

\begin{abstract}
A B S T R A C T
Purpose

When discussing the transition to palliative care for patients with breast cancer, oncologists have to find a balance between giving explicit information while not overwhelming patients and being realistic while remaining hopeful. It is unclear whether patients prefer more or less explicit prognostic information, and reassuring patients that they will not be abandoned may provide realistic hope. We assessed the effect of explicit prognostic information and reassurance about nonabandonment at the transition to palliative care.
\end{abstract}

Patients and Methods

An experimental $2 \times 2$ study was used. Four scripted videos of a bad news conversation were created that differed only in the level of "explicitness of prognosis" and "reassurance about nonabandonment" (high v low). Patients with and survivors of breast cancer $(n=51)$ and healthy women $(n=53)$ watched the video-vignettes. The effects of the different communications on participants' anxiety, uncertainty, self-efficacy, and satisfaction were assessed by using multilevel analyses that explored the moderating influences of monitoring/blunting scores.

Results

The highly explicit/highly reassuring video yielded the most positive outcomes, and the less explicit/less reassuring video, the most negative ( $\mathrm{P} \leq .05$ for all outcome measures except anxiety). The main effects found were that explicitness and reassurance decreased participants' uncertainty $(\mathrm{P}<.001$ and $\mathrm{P}$ $=.002$, respectively) and anxiety (only after reassurance; $\mathrm{P}_{-} .001$ ) while increasing self-efficacy $(\mathrm{P}=.004$ and $\mathrm{P}<.001$, respectively) and satisfaction $(\mathrm{P}$ 
$<.001$ and $\mathrm{P}<.001$, respectively). High monitors seemed least positive, mainly

following explicitness.

Conclusion

Explicit prognostic information may lead to better outcomes than general information. In addition, reassurance about nonabandonment might provide realistic hope but should be lived up to. More research is needed to translate these findings into clinical care.

\section{INTRODUCTION}

Bad news such as the transition to palliative care can evoke many feelings in patients, including uncertainty ${ }^{1-4}$ and anxiety. ${ }^{2,3}$ Meanwhile, patients have two distinct needs in such situations: to "know and understand" and to "feel known and understood." ${ }^{5,6}$ The provision of information and empathy (ie, instrumental $v$ affective care ${ }^{5,7}$ ) can satisfy these needs and influence distinct outcomes ${ }^{8}$ such as uncertainty and anxiety. Meanwhile, oncologists have to walk the fine line between giving complete information while not overwhelming patients ${ }^{9}$ and being realistic while remaining hopeful. ${ }^{10-12}$ Most patients want information about their life expectancy, ${ }^{13,14}$ but the level of explicitness they desire varies. ${ }^{15}$ Patients often request full disclosure, ${ }^{16,17}$ but some prefer to remain partly ignorant about their life expectancy. ${ }^{16,18,19}$ It is still unclear whether numerical data or qualitative words are preferred when discussing future expectations. ${ }^{16,20}$ Unsurprisingly, the prognostic part of consultations is often problematic. ${ }^{20-22}$ Because not all patients want to know everything, ${ }^{10,23}$ oncologists sometimes avoid providing statistical information, regardless of patients' preferences. ${ }^{24-26}$ Next, patients have a need for hope, ${ }^{2,27-29}$ which can mainly be seen as an affective need. In a previous qualitative study, we found that participants were "afraid they would be left alone" when entering palliative care, and being reassured that they would not be abandoned might provide hope. ${ }^{15}$ Indeed, patients want-and thereby may experience hope- to be sure that they will be continuously guided in their care trajectory ${ }^{30}$ and that the relationship with their oncologist will continue.

${ }^{31}$ Moreover, they want a discussion of their prognosis to include a commitment about nonabandonment. ${ }^{32}$ Authors ${ }^{33-35}$ and guidelines ${ }^{36,37}$ have noted how important being taken care of is to patients but it has not often been mentioned as an essential component when delivering bad news.

Meanwhile, patients' coping styles might influence their communication preferences. According to the coping literature, people in threatening situations usually choose between approach and avoidance.

${ }^{38}$ In the medical consultation context this means seeking or avoiding information. This is what the coping styles of monitoring and blunting aim to measure. ${ }^{39-41}$ High monitors are found to have high needs for information ${ }^{42-44}$ and for emotional support, ${ }^{42,43,45}$ and high blunters prefer to avoid threatening information. ${ }^{39,40}$ However, investigation is warranted into the influence of these coping styles at the transition to palliative care.

The aim of this study is to examine the effect of more versus less explicit prognostic information and reassurance about nonabandonment at the transition to palliative 
care. We hypothesize that more explicit prognostic information (instrumental communication) will decrease mainly uncertainty (an instrumental outcome) but also anxiety (an affective outcome), especially for high monitors but not for high blunters. Moreover, we expect that reassurance about nonabandonment (affective communication) will decrease mainly anxiety but also uncertainty, especially for high monitors. Both explicitness and reassurance might also positively influence related measures such as self-efficacy (since it can be argued that a life-limiting diagnosis shatters this belief) and satisfaction (a widely assessed and influenced outcome of patients' perceptions of care).

\section{PATIENTS AND METHODS}

\section{Videotape Development}

An experimental study with a 2X2 design was used to investigate the two abovementioned communication elements. Four scripted video-vignettes were developed of a consultation in which an oncologist discussed the transition to palliative care with a female patient who had breast cancer. These video-vignettes were identical in content and communication, but the "explicitness of prognosis" and "reassurance about nonabandonment" varied systematically between the vignettes (high or low; Table 1). The scripts and manipulations were based on a qualitative study that focused on the abovementioned dilemmas, ${ }^{15}$ the biomedical/communicative expertise of the authors, and videos of bad news consultations and prior scripted studies. An introductory video was developed in which the video-patient introduced herself and expressed her feelings about the upcoming consultation, which aimed to increase participants' empathic involvement. Toensure the scripts' internal/ external validity, both lay people (breast cancer survivors, healthy women)and experts (oncologists, communication experts) were involved in creating the written and role-playing scripts. Professional actors role-played the scripts.

Detailed information about this process and the final scripts is provided elsewhere ${ }^{46}$; the exact manipulations are displayed in Table 2.

\section{[TABLE 1] [TABLE 2]}

\section{Participants}

Patients with and survivors of breast cancer and healthywomenage 18 to 65 years, with sufficient command of Dutch, were recruited through patient advocacy organizations, health-related Web sites, and message boards and by using snowball procedures. Ethnic minority women were recruited through a patient advocacy organization and social workers (using their network).

Women participated as analog patients (APs); they viewed the videos while putting themselves in the shoes of the video-patient. The validity of this approach is documented. ${ }^{47}$ On the basis of a previous study that used a similar design, ${ }^{48}$ a sample size of 93 was required to give $80 \%$ power to detect two main effects and one interaction effect using a two-sided $\alpha=.05$ and an interclass correlation coefficient (ICC) of 0.20. To control for order effects, we used complete counterbalancing; we therefore aimed to include 96 women (24 X 2 X 2). ${ }^{49}$ 


\section{Procedure}

The study was approved by the Medical Ethics Committee of the University Medical Center of Utrecht. Women's background characteristics were assessed before the experiment. Groups of one to seven women were set up separately for patients/survivors and healthy women. After informed consent was obtained, APs were asked to identify with the video-patient. First, they watched the introduction video and the first part of the bad news consultation.

Then they watched the four different videos. Anxiety was assessed before each video and all outcome measures were completed after each video.Adistraction task was provided between the videos (looking at an aquarium while listening to background classical music).

\section{Background Measures}

We measured the following characteristics: demographic variables, health status (Dartmouth COOP [from the Dartmouth Primary Care Cooperative Information Project known as the "CO-OP Project"] functional health assessment charts/World Organization of National Colleges, Academies, and Academic Associations of General Practices/Family Physicians [COOP/ WONCA $]^{50}$ ), trait anxiety (State-Trait Anxiety Inventory [STAI]-Trait ${ }^{51}$ ), optimism (Life Orientation Test-Revised [LOT$\mathrm{R}]^{52}$ ), whether participants had experiences with loved ones receiving a life-limiting cancer diagnosis ("similar experiences"), and monitoring/blunting coping styles (Threatening Medical Situations Inventory [TMSI] shortened version. ${ }^{44}$ Blunting was measured with the five items used in the analyses by Onget $\mathrm{al}^{44}$ but was recoded for all analyses to a six-item scale that facilitated comparison with the six-item monitoring scale). Trait anxiety, ${ }^{18,53}$ optimism, ${ }^{54}$ and similar experiences ${ }^{15,55}$ were measured because they might influence communication preferences.

\section{Main Outcome Measures}

Uncertainty (0 to 100 self-created visual analog scale [VAS], ranging from "very certain" to "very uncertain") and anxiety (STAI-State ${ }^{51}$ ) were main outcome measures. Cronbach's alphas for the STAI-State before and after the video were .90 and .84, respectively. The difference score between the prevideo and postvideo STAI-State score was used in all analyses. To lessen the burden of filling in numerous questionnaires in the groups with immigrant women, the STAI-State beforehand was measured only before the first video. This prescore was used to determine difference scores for each video.

\section{Secondary Outcome Measures}

Secondary outcome measures were self-efficacy (0 to 100 self-created VAS, ranging from very little to very great belief in ability to deal with the future) and satisfaction (Patient Satisfaction Questionnaire [PSQ] ${ }^{56}$ ).

The reliability of the PSQ was 0.90 in this sample. The success of the manipulations - how explicit the prognostic information was perceived as being and how reassuring the oncologist was (about nonabandonment) — was measured by using 1 to 10 scales ("not at all" to "very"; not measured in the ethnic minority groups). 


\section{Analyses}

First, independent samples $t$ tests and $\chi^{2}$ tests were performed to compare the background characteristics of patients/survivors and healthy women.

Variables that differed between the two groups were included in step 4 to determine their effect on outcome measures. For subsequent analyses — as participants watched four videos - random intercept linear multilevel regressions were applied, consisting of videos (level 1) nested in participants (level 2).

Second, we analyzed whether the data for healthy women and patients/survivors could be pooled. Third, the manipulation successes were determined.

Fourth, the influence of the following demographic characteristics on outcome measures was assessed, because they could have influenced communication preferences: age, trait anxiety, optimism, education, similar experiences, and ethnicity. The three variables with the strongest effects on outcomes were entered as (centered) covariates in the subsequent models. This number was chosen because of power constraints. Fifth, the effect of the four videos on all outcome measures was determined. Bonferroni post hoc tests were applied to determine which videos influenced outcomes significantly differently.

Sixth, the main and interaction effects of explicitness and reassurance were calculated (interaction effects were eliminated from the model when not significant). Last, the moderating influences of monitoring and blunting scores on the effects of the four videos and the effects of explicitness and reassurance were explored. To do that, interaction effects between monitoring/ blunting and the videos/explicitness/reassurance were created. For steps 6 and 7, we transformed all outcome measures into Fisher z (for normalization).

Analyses were conducted by using Stata 12.0 with two-sided significance testing at $P \leq .05$.

\section{RESULTS}

\section{Sample}

Demographic characteristics of the 51 patients/survivors and 53 healthy women who participated in the study largely overlapped (Table 3). That said, patients/survivors were older $(P<.001)$ and their health status was poorer $(P=.003)$ compared with healthy women.

\section{Pooling of Data}

Patients/survivors and healthy women did not respond differently to the four videos (Appendix Table A1, online only). The groups were therefore pooled for the main multilevel models, and health status was entered as an additional possible covariate.

\section{Manipulation Check}

The manipulations succeeded. In the highly explicit videos, the prognosis was evaluated as being more explicit than in the less explicit videos (high: mean, 5.96; SE, 0.19; low: mean, 3.69; SE, 0.19; $P<.001$ ).

The same results applied to the highly versus less reassuring videos (high: mean, 7.22; SE, 0.18; low: mean, 4.25; SE, 0.18; $P<.001$ ). 


\section{Covariates}

The three background characteristics with the strongest effects on outcome measures were trait anxiety ( $P=.004$, self-efficacy), optimism ( $P=.009$, self-efficacy), and education $(P<.001$, anxiety).

These variables were entered as (centered) covariates in the subsequent models. The following characteristics (not included) also influenced outcomes: similar experiences ( $P=.027$, anxiety) and ethnicity ( $P=.026$, anxiety; $P=.027$, self-efficacy).

\section{Effects of the Four Videos}

Controlled multilevel models showed that the videos had an effect on all the outcome measures $(P<.02)$ but no order effects (data not shown). The lowest scores for uncertainty and anxiety along with the highest scores for self-efficacy and satisfaction were obtained when the oncologist was both explicit and reassuring. In contrast, the most negative reactions were found following the less explicit/less $\mathrm{X}$ video-vignette. Bonferroni post hoc tests revealed that these differences were significant $(P \leq .05)$ for all outcome measures except for anxiety $(P=.06)$. Furthermore, the combination of explicitness and reassurance was better evaluated than either one alone. In the highly explicit/less reassuring condition, poorer results were found for uncertainty $(P=.01)$, self-efficacy $(P<.001)$, and satisfaction $(P<.001)$. After the highly reassuring/less explicit video, APs were more uncertain $(P<.001)$ and less satisfied $(P=.002$; Table 4$)$.

\section{Main Effects and Interaction Effects of Explicitness and Reassurance}

To illustrate the individual and combined contributions of explicitness and reassurance, controlled multilevel analyses were determine the main effects and interaction effects.

\section{[TABLE 3]}

Only main effects were found. Explicitness decreased APs' uncertainty $(P<.001)$ but not anxiety $(P=.562)$ while increasing self-efficacy $(P=.004)$ and satisfaction $(P<.001)$. Reassurance decreased uncertainty $(P=.002)$ and anxiety $(P=.001)$ while increasing self-efficacy $(P \leq .001)$ and satisfaction $(P \leq .001$; Table 5$)$.

\section{Moderating Influences of Monitoring and Blunting}

Exploratory analyses showed that, compared with low monitors, high monitors were more uncertain $(P=.031)$ and anxious $(P=.037)$ after seeing the highly explicit/highly reassuring video and less anxious $(P=.045)$ after the less explicit/highly reassuring video. Explicit prognostic information made them more uncertain $(P=.007)$ and anxious $(P=.007)$ and less self-efficacious $(P=.012)$ and satisfied $(P=.048)$. Blunting scores had no moderating influences (Table 6).

\section{DISCUSSION}

By using a scripted video-vignette design, the effects of explicit prognostic information and reassurance about nonabandonment at the transition to palliative breast cancer care were assessed. Our results showed that (a combination of) explicit 
Vliet, L.M. van, Wall, E. van der, Plum, N.M., Bensing, J.M. Explicit prognostic information andreassurance about nonabandonment when entering palliative breast cancer care: findings from a scripted video-vignette study. Journal of Clinical Oncology: 2013, 31(26), 3242-3249

prognostic reassurance about nonabandonment was most positively evaluated by patients with and survivors of breast cancer and healthy women.

\section{[TABLE 4][TABLE 5]}

Explicit prognostic information yielded better outcomes than general information, which corresponds to clinical patients' preferences for full disclosure. ${ }^{16,57}$ Precise information decreased women's uncertainty while increasing self-efficacy. Clinical patients often report that uncertainty is worse than the certainty bad news creates. ${ }^{58,59}$ Whereas excessively vague information increases distress, ${ }^{14,60}$ precise information about their condition helps patients $\operatorname{plan}^{16}$ and make treatment decisions. ${ }^{61,62}$ The importance of unambiguous information is stressed by a recent finding that many patients receiving palliative chemotherapy wrongly believe in its curative potential. ${ }^{63}$ Moreover, our results showed that three affective statements giving reassurance about nonabandonment influenced anxiety and other outcomes. Indeed, the certainty of continuing care seems to be a hopeful theme for clinical patients. ${ }^{30,31}$ Patients want to be looked after, ${ }^{31}$ which was also described as hope-giving in our previous study. ${ }^{15}$ Emphasizing continuing care may thus be a promising way to satisfy patients' desire for hope while remaining realistic.

Interestingly, reassurance decreased anxiety and uncertainty, while explicitness decreased only uncertainty. Anxiety, an affective measure, may be insensitive to instrumental communication, ${ }^{64}$ which also explains our borderline significant differences for anxiety when comparing effects of the vignettes with Bonferroni tests.

Conversely, in addition to decreasing anxiety, reassurance can evoke the feeling of unconditional guidance, ${ }^{30}$ which might decrease uncertainty and increase perceived self-efficacy. Affective communication does indeed influence several outcomes ${ }^{65}$ including self-efficacy. ${ }^{66}$ Finally, satisfaction was influenced by reassurance and explicitness, possibly because the PSQ includes affective and instrumental items, both influencing satisfaction. ${ }^{67}$ So, although explicitness and reassurance have distinct influences, the combination seems most promising in bad news consultations.

Contrary to our expectations, high monitors seemed to benefit least from these communications. This result corresponds with previous studies, which concluded that high monitors are often less satisfied with information than low monitors. ${ }^{68,69}$

However, other studies concluded that high monitors are generally the ones benefitting the most from detailed information. ${ }^{70,71}$ The question remains which communication style yields the best outcome for high monitors when they are entering palliative care.

Our findings have implications for clinical care. The explicit prognostic discussion, including statistical information, yielded better results than the general discussion. This might be helpful for oncologists who are reluctant to discuss statistical information because of its uncertain utility for and effect on individuals. ${ }^{72,73} \mathrm{We}$ found that stressing the difficulty of predicting an individual's survival, emphasizing that numbers are based on large groups, and that there are negative and positive exceptions might be a beneficial approach when discussing prognosis in detail. This corresponds to recently proposed strategies, which focus on stressing the impossibility of predicting where a patient will fall on a statistical survival curve ${ }^{74}$ or 
Vliet, L.M. van, Wall, E. van der, Plum, N.M., Bensing, J.M. Explicit prognostic information andreassurance about nonabandonment when entering palliative breast cancer care: findings from a scripted video-vignette study. Journal of Clinical Oncology: 2013, 31(26), 3242-3249

mentioning outliers next to means. ${ }^{75,76}$ Indeed, patients who prefer openness about their prognosis appreciate the emphasis on the uncertainty in the statistics. ${ }^{20,77}$ However, a minority of patients prefer to be left partly ignorant about their prognosis, ${ }^{16,18,19}$ which emphasizes the importance of determining patients' information needs before discussing the prognosis.

In our study, the patient asked for explicit or general prognostic information and the oncologist checked her wish for explicitness before providing this information, which is in line with current recommendations ${ }^{78,79}$ and our previous study. ${ }^{15}$ Because we did not manipulate patient communication in this experiment, we cannot draw any conclusions on how oncologists should respond to patients who do not prompt the doctor for information. It is worth noting that our results suggest that high monitors, who often ask many questions, ${ }^{44,68}$ might not be the ones who benefit the most after receiving explicit life-limiting prognostic information (and reassurance).

\section{[TABLE 6]}

After our positive results regarding reassurance about nonabandonment, oncologists may decide to implement such statements to] offer realistic hope. Promising not to abandon patients is one thing; however, doing so is another. Oncologists, who seem increasingly aware of the importance of nonabandonment, ${ }^{31,74,80}$ may eventually fail this task, often because the patient is referred to hospice care. ${ }^{31}$ Han and Arnold ${ }^{81}$ suggested that patients' primary physicians should not withdraw after referring to hospice care, but if it becomes necessary, they should discuss their withdrawal with patients beforehand.

Several national cancer organizations ${ }^{82-85}$ advise that general practitioners should have a (continuous) role in palliative care. Others point toward the positive effects of introducing palliative care teams early on in this phase. ${ }^{86-88}$ Implementation of such initiatives might benefit patients who feel abandoned when familiar care providers are suddenly unavailable. ${ }^{30,74}$ So, although there is a need to educate future oncologists about the potential power of expressing nonabandonment, ${ }^{89}$ there is first and foremost a need to determine how this promise can best be given and kept in busy clinical daily life.

This study has limitations. First, we conducted an experimental study with APs, so clinical patients in this situation might respond differently. Still, in a recent systematic review, we found that APs' perceptions are valid, ${ }^{47}$ and the perceptions of patients with and survivors of cancer versus healthy women overlapped in this study. Second, participants viewed four videos varying slightly in communication. Although we varied the order of viewing the videos, and a pilot study indicated that participants could focus on four videos, a habituation effect may have occurred for some individuals. Third, because of our recruitment methods (eg, through advocacy organizations), our sample might be biased, and less-involved women may be underrepresented.

Fourth, experimental designs inherently reduce the complexity of clinical interactions, which stresses the importance of clinical follow-up studies. Last, the limited sample size of our study hampered the analysis of the influence of several background characteristics such as ethnicity.

Future studies might focus on the most beneficial and feasible approach to discussing statistical information from the perspective of patients in clinical care. More research is needed on how nonabandonment can best be promised (and how that promise can 
Vliet, L.M. van, Wall, E. van der, Plum, N.M., Bensing, J.M. Explicit prognostic information andreassurance about nonabandonment when entering palliative breast cancer care: findings from a scripted video-vignette study. Journal of Clinical Oncology: 2013, 31(26), 3242-3249

be kept) in palliative care. Furthermore, studies into other types of individualized reassurance (eg, regarding pain control) would be worthwhile. Specific attention should be paid to the influence of background characteristics on communication needs and evaluations, starting with the influence of monitoring scores.

In conclusion, although more research is needed to translate our findings into clinical care, the results presented once again underline the power of communication. In the current climate of personalized care, explicit and reassuring information might be beneficial for most patients, although investigating and acting on individual's specific preferences should never be neglected.

\section{REFERENCES}

1. Benzein E, Norberg A, Saveman BI: The meaning of the lived experience of hope in patients with cancer in palliative home care. Palliat Med 15:117-126, 2001

2. Evans WG, Tulsky JA, Back AL, et al: Communication at times of transitions: How to help patients cope with loss and re-define hope. Cancer J 12:417-424, 2006

3. Anderson WG, Alexander SC, Rodriguez KL, et al: "What concerns me is . .." Expression of emotion by advanced cancer patients during outpatient visits. Support Care Cancer 16:803-811, 2008

4. Jeffrey D: Appropriate palliative care: When does it begin? Eur J Cancer Care (Engl) 4:122-126, 1995

5. Bensing J, Schreurs K, de Rijk A: The role of the general practitioner's affective behaviour in medical encounters. Psychol Health 11:825-838, 1996

6. Engel GL: How much longer must medicine's science be bound by a seventeenth century world view? Psychother Psychosom 57:3-16, 1992

7. Bensing JM, Dronkers J: Instrumental and affective aspects of physician behavior. Med Care 30:283-298, 1992

8. de Haes $\mathrm{H}$, Bensing J: Endpoints in medical communication research, proposing a framework of functions and outcomes. Patient Educ Couns 74: 287-294, 2009

9. Back AL, Anderson WG, Bunch L, et al: Communication about cancer near the end of life. Cancer 113:1897-1910, 2008

10. Innes S, Payne S: Advanced cancer patients' prognostic information preferences: A review. Palliat Med 23:29-39, 2009

11. Schapira L, Butow P, Brown R, et al: Pessimism is no poison. J Clin Oncol 28:705-707, 2010

12. Fallowfield L, Jenkins V: Communicating sad, bad, and difficult news in medicine. Lancet 363:312- 319, 2004

13. Hagerty RG, Butow PN, Ellis PM, et al: Communicating prognosis in cancer care: A systematic review of the literature. Ann Oncol 16:1005-1053, 2000

14. Kirk P, Kirk I, Kristjanson LJ: What do patients receiving palliative care for cancer and their families want to be told? A Canadian and Australian qualitative study. BMJ 328:1343, 2004

15. van Vliet L, Francke A, Tomson S, et al: When cure is no option: How explicit and hopeful can information be given? A qualitative study in breast cancer. Patient Educ Couns 90:315-322, 2013

16. Hagerty RG, Butow PN, Ellis PA, et al: Cancer patient preferences for communication of prognosis in the metastatic setting. J Clin Oncol 22:1721-1730, 2004

17. Pardon K, Deschepper R, Vander Stichele R, et al: Are patients' preferences for information and participation in medical decision-making being met? Interview study with lung cancer patients. Palliat Med 25:62-70, 2011

18. Kaplowitz SA, Campo S, Chiu WT: Cancer patients' desires for communication of prognosis information. Health Commun 14:221-241, 2002

19. Barnett MM: Does it hurt to know the worst? Psychological morbidity, information preferences and understanding of prognosis in patients with advanced cancer. Psychooncology 15: 44-55, 2006 
Vliet, L.M. van, Wall, E. van der, Plum, N.M., Bensing, J.M. Explicit prognostic information and reassurance about nonabandonment when entering palliative breast cancer care: findings from a scripted video-vignette study. Journal of Clinical Oncology: 2013, 31(26), 3242-3249

20. Clayton JM, Butow PN, Arnold RM, et al: Discussing life expectancy with terminally ill cancer patients and their carers: A qualitative study. Support Care Cancer 13:733-742, 2005

21. Rogg L, Loge JH, Aasland OG, et al: Physicians' attitudes towards disclosure of prognostic information: A survey among a representative crosssection of 1605 Norwegian physicians. Patient Educ Couns 77:242-247, 2009

22. Smith TJ, Longo DL: Talking with patients about dying. N Engl J Med 367:1651-1652, 2012 23. Leydon GM, Boulton M, Moynihan C, et al: Faith, hope, and charity: An in-depth interview study of cancer patients' information needs and information-seeking behavior. West J Med 173:26- 31, 2000

24. Rogg L, Aasland OG, Graugaard PK, et al: Direct communication, the unquestionable ideal? Oncologists' accounts of communication of bleak prognoses. Psychooncology 19:1221-1228, 2010

25. Lamont EB, Christakis NA: Prognostic disclosure to patients with cancer near the end of life. Ann Intern Med 134:1096-1105, 2001

26. Gordon EJ, Daugherty CK: 'Hitting you over the head': oncologists' disclosure of prognosis to advanced cancer patients. Bioethics 17:142-168, 2003

27. Clayton JM, Hancock K, Parker S, et al: Sustaining hope when communicating with terminally ill patients and their families: A systematic review.

Psychooncology 17:641-659, 2008

28. Hagerty RG, Butow PN, Ellis PM, et al: Communicating with realism and hope: Incurable cancer patients' views on the disclosure of prognosis. J Clin Oncol 23:1278-1288, 2005

29. Daneault S, Dion D, Sicotte C, et al: Hope and noncurative chemotherapies: Which affects the other? J Clin Oncol 28:2310-2313, 2010

30. Stajduhar KI, Thorne SE, McGuinness L, et al: Patient perceptions of helpful communication in the context of advanced cancer. J Clin Nurs 19:2039- 2047, 2010

31. Back AL, Young JP, McCown E, et al: Abandonment at the end of life from patient, caregiver, nurse, and physician perspectives: Loss of continuity and lack of closure. Arch Intern Med 169:474- 479, 2009

32. Curtis JR, Engelberg R, Young JP, et al: An approach to understanding the interaction of hope and desire for explicit prognostic information among individuals with severe chronic obstructive pulmonary disease or advanced cancer. J Palliat Med 11:610-620, 2008

33. Quill TE, Cassel CK: Nonabandonment: A central obligation for physicians. Ann Intern Med 122: 368-374, 1995

34. Byock IR: The nature of suffering and the nature of opportunity at the end of life. Clin Geriatr Med 12:237-252, 1996

35. Dias L, Chabner BA, Lynch TJ Jr, et al: Breaking bad news: A patient's perspective. Oncologist 8:587-596, 2003

36. Schofield P, Carey M, Love A, et al: 'Would you like to talk about your future treatment options'? Discussing the transition from curative cancer treatment to palliative care. Palliat Med 20:397-406, 2006

37. Baile WF, Buckman R, Lenzi R, et al: SPIKES: A six-step protocol for delivering bad news-Application to the patient with cancer. Oncologist 5:302-311, 2000

38. Roth S, Cohen LJ: Approach, avoidance, and coping with stress. Am Psychol 41:813819, 1986

39. Miller SM: Monitoring versus blunting styles of coping with cancer influence the information patients want and need about their disease: Implications for cancer screening and management. Cancer 76:167-177, 1995

40. Miller SM: Monitoring and blunting: Validation of a questionnaire to assess styles of information seeking under threat. J Pers Soc Psychol 52:345- 353, 1987

41. Miller SM, Brody DS, Summerton J: Styles of coping with threat: Implications for health. J Pers Soc Psychol 54:142-148, 1988

42. Parker PA, Baile WF, de Moor C, et al: Breaking bad news about cancer: Patients' preferences for communication. J Clin Oncol 19:2049-2056, 2001

43. van Weert JC, Jansen J, de Bruijn GJ, et al: QUOTEchemo: A patient-centred instrument to measure quality of communication preceding chemotherapy treatment through the patient's eyes. Eur J Cancer 45:2967-2976, 2009 
Vliet, L.M. van, Wall, E. van der, Plum, N.M., Bensing, J.M. Explicit prognostic information and reassurance about nonabandonment when entering palliative breast cancer care: findings from a scripted video-vignette study. Journal of Clinical Oncology: 2013, 31(26), 3242-3249

44. Ong LM, Visser MR, van Zuuren FJ, et al: Cancer patients' coping styles and doctorpatient communication. Psychooncology 8:155-166, 1999

45. Pieterse A, van Dulmen S, Ausems M, et al: QUOTE-gene(ca): Development of a counseleecentered instrument to measure needs and preferences in genetic counseling for hereditary cancer.

Psychooncology 14:361-375, 2005

46. van Vliet LM, Hillen MA, van der Wall E, et al: How to create and administer scripted videovignettes in an experimental study on disclosure of a palliative breast cancer diagnosis. Patient Educ Couns 91:56-64, 2013

47. van Vliet LM, van der Wall E, Albada A, et al: The validity of using analogue patients in practitioner-patient communication research: Systematic review and meta-analysis. J Gen Intern Med 27:1528-1543, 2012

48. Fogarty LA, Curbow BA, Wingard JR, et al: Can 40 seconds of compassion reduce patient anxiety? J Clin Oncol 17:371-379, 1999

49. Shadish WR, Cook TD, Campbell DT: Experimental and Quasi-Experimental Designs for Generalized Causal Inference. Boston, MA, Houghton Mifflin, 2002

50. Van Weel C: Functional status in primary care: COOP/WONCA charts. Disabil Rehabil 15:96-101, 1993

51. Spielberger CD, Gorsuch RL, Lushene RE: STAI Manual for the State-Trait Anxiety Inventory. Palo Alto, CA, Consulting Psychologists Press, 1970

52. Scheier MF, Carver CS, Bridges MW: Distinguishing optimism from neuroticism (and trait anxiety, self-mastery, and self-esteem): A reevaluation of the Life Orientation Test. J Pers Soc Psychol 67:1063-1078, 1994

53. Graugaard PK, Finset A: Trait anxiety and reactions to patient-centered and doctorcentered styles of communication: An experimental study. Psychosom Med 62:33-39, 2000

54. Wong F, Stewart DE, Dancey J, et al: Men with prostate cancer: Influences of psychological factors on informational needs and decision making. J Psychosom Res 49:13-19, 2000

55. Marwit SJ, Datson SL: Disclosure preferences about terminal illness: An examination of decision-related factors. Death Stud 26:1-20, 2002

56. Zandbelt LC, Smets EM, Oort FJ, et al: Satisfaction with the outpatient encounter: A comparison of patients' and physicians' views. J Gen Intern Med 19:1088-1095, 200457. Jenkins V, Fallowfield L, Saul J: Information needs of patients with cancer: Results from a large study in UK cancer centres. Br J Cancer 84:48-51, 2001

58. Yardley SJ, Davis CL, Sheldon F: Receiving a diagnosis of lung cancer: Patients' interpretations, perceptions and perspectives. Palliat Med 15:379- 386, 2001

59. Randall TC, Wearn AM: Receiving bad news: Patients with haematological cancer reflect upon their experience. Palliat Med 19:594-601, 2005

60. Wenrich MD, Curtis JR, Shannon SE, et al: Communicating with dying patients within the spectrum of medical care from terminal diagnosis to death. Arch Intern Med 161:868-874, 2001

61. Audrey S, Abel J, Blazeby JM, et al: What oncologists tell patients about survival benefits of palliative chemotherapy and implications for informed consent: Qualitative study. BMJ 337:a752, 2008

62. Parker PA, Aaron J, Baile WF: Breast cancer: Unique communication challenges and strategies to address them. Breast J 15:69-75, 2009

63. Weeks JC, Catalano PJ, Cronin A, et al: Patients' expectations about effects of chemotherapy for advanced cancer. N Engl J Med 367:1616-1625, 2012

64. de Bie RP, Massuger LF, Lenselink $\mathrm{CH}$, et al: The role of individually targeted information to reduce anxiety before colposcopy: A randomised controlled trial. BJOG 118:945-950, 2011

65. Lelorain S, Bre' dart A, Dolbeault S, et al: A systematic review of the associations between empathy measures and patient outcomes in cancer care. Psychooncology 21:1255-1264, 2012

66. Zachariae R, Pedersen CG, Jensen AB, et al: Association of perceived physician communication style with patient satisfaction, distress, cancerrelated self-efficacy, and perceived control over the disease. Br J Cancer 88:658-665, 2003 
Vliet, L.M. van, Wall, E. van der, Plum, N.M., Bensing, J.M. Explicit prognostic information and reassurance about nonabandonment when entering palliative breast cancer care: findings from a scripted video-vignette study. Journal of Clinical Oncology: 2013, 31(26), 3242-3249

67. Venetis MK, Robinson JD, Turkiewicz KL, et al: An evidence base for patient-centered cancer care: A meta-analysis of studies of observed communication between cancer specialists and their patients. Patient Educ Couns 77:379-383, 2009

68. Timmermans LM, van Zuuren FJ, van der Maazen RW, et al: Monitoring and blunting in palliative and curative radiotherapy consultations. Psychooncology 16:1111-1120, 2007

69. Steptoe A, Sutcliffe I, Allen B, et al: Satisfaction with communication, medical knowledge, and coping style in patients with metastatic cancer. Soc Sci Med 32:627-632, 1991

70. Miller SM, Mangan CE: Interacting effects of information and coping style in adapting to gynecologic stress: Should the doctor tell all? J Pers Soc Psychol 45:223-236, 1983

71. Kola S, Walsh JC, Hughes BM, et al: Matching intra-procedural information with coping style reduces psychophysiological arousal in women undergoing colposcopy. J Behav Med 10.1007/s10865- 012-9435-z [epub ahead of print on June 24, 2012]

72. Hancock K, Clayton JM, Parker SM, et al: Truth-telling in discussing prognosis in advanced life-limiting illnesses: A systematic review. Palliat Med 21:507-517, 2007

73. Elit L, Charles C, Gafni A, et al: Walking a tightrope: Oncologists' perspective on providing information to women with recurrent ovarian cancer (ROC) during the medical encounter. Support Care Cancer 20:2327-2333, 2012

74. Rosenblum ML, Kalkanis S, Goldberg W, et al: Odyssey of hope: A physician's guide to communicating with brain tumor patients across the continuum of care. J Neurooncol 92:241-251, 2009

75. Back AL, Arnold RM: Discussing prognosis: "How much do you want to know?" Talking to patients who are prepared for explicit information. J Clin Oncol 24:4209-4213, 2006

76. Kiely BE, Tattersall MH, Stockler MR: Certain death in uncertain time: Informing hope by quantifying a best case scenario. J Clin Oncol 28:2802- 2804, 2010

77. Thorne S, Hislop TG, Kuo M, et al: Hope and probability: Patient perspectives of the meaning of numerical information in cancer communication. Qual Health Res 16:318-336, 2006

78. Campbell TC, Carey EC, Jackson VA, et al: Discussing prognosis: Balancing hope and realism. Cancer J 16:461-466, 2010

79. Rodin G, Mackay JA, Zimmermann C, et al: Clinician-patient communication: A systematic review. Support Care Cancer 17:627-644, 2009

80. Morales La Madrid A: Waiting for a miracle. J Clin Oncol 30:2421-2422, 2012

81. Han PK, Arnold RM: Palliative care services, patient abandonment, and the scope of physicians' responsibilities in end-of-life care. J Palliat Med 8:1238-1245, 2005

82. Ngo-Metzger Q, August KJ, Srinivasan M, et al: End-of-Life care: Guidelines for patientcentered communication. Am Fam Physician 77:167-174, 2008

83. Knottnerus JA, Wijffels JFAM: Nazorg bij kanker: De rol van de eerste lijn. [Aftercare in cancer: The role of the first line]. Amsterdam, the Netherlands, Dutch Cancer Organization, publication 978-90-71229-22-0, 2011

84. Hibble A: Care of people with cancer and palliative care. London, United Kingdom, Royal College of General Practitioners Curriculum Statement, Version 1.2, 2011

85. Cancer Care Ontario: Regional Models of Care for Palliative Cancer Care:

Recommendations for the Organization and Delivery of Palliative Cancer Care in Ontario. Provincial Palliative Care Program, December, 2009

https://www.cancercare.on.ca/common/pages/ UserFile.aspx?fileld_77326

86. Smith TJ, Temin S, Alesi ER, et al: American Society of Clinical Oncology provisional clinical opinion: The integration of palliative care into standard oncology care. J Clin Oncol 30:880-887, 2012

87. Pirl WF, Greer JA, Traeger L, et al: Depression and survival in metastatic non-small-cell lung cancer: Effects of early palliative care. J Clin Oncol 30:1310-1315, 2012

88. Bruera E, Hui D: Integrating supportive and palliative care in the trajectory of cancer: Establishing goals and models of care. J Clin Oncol 28:4013-4017, 2010

89. Cherny N: The oncologist's role in delivering palliative care. Cancer J 16:411-422, 2010 
Vliet, L.M. van, Wall, E. van der, Plum, N.M., Bensing, J.M. Explicit prognostic information and

TABLE

Table 1. Communication in the Four Video-Vignettes

\begin{tabular}{llll}
\hline \multicolumn{1}{c}{ Video 1 } & \multicolumn{1}{c}{ Video 2 } & \multicolumn{1}{c}{ Video 3 } & \multicolumn{1}{c}{ Video 4 } \\
\hline Explicit+ & Explicit+ & Explicit - & Explicit- \\
Reassurance+ & Reassurance - & Reassurance+ & Reassurance- \\
\hline
\end{tabular}

NOTE. Plus and minus signs indicate high and low, respectively. 
Vliet, L.M. van, Wall, E. van der, Plum, N.M., Bensing, J.M. Explicit prognostic information andreassurance about nonabandonment when entering palliative breast cancer care: findings from 1 a scripted video-vignette study. Journal of Clinical Oncology: 2013, 31(26), 3242-3249

Table 2. Exact Manipulations Used in the Four Different Videos

\begin{tabular}{|c|c|}
\hline Manipulation & Exact Content \\
\hline \multirow[t]{8}{*}{ Explicit high } & Patient: Okay, so how long have I got? \\
\hline & Oncologist: Your life expectancy? \\
\hline & $\begin{array}{l}\text { Patient: Yes, I would like to know that as specifically } \\
\text { as possible. }\end{array}$ \\
\hline & $\begin{array}{l}\text { Oncologist: That's very difficult. But I can give you } \\
\text { some concrete numbers and averages. Would } \\
\text { you like me to discuss these with you? }\end{array}$ \\
\hline & Patient: Yes. \\
\hline & $\begin{array}{l}\text { Oncologist: When we look at what is known from } \\
\text { studies with patients with your type of cancer cell } \\
\text { and your metastases, } 50 \% \text { of the patients are still } \\
\text { alive after } 2 \text { years. So, half the people will die } \\
\text { within } 2 \text { years, while the other half will live longer } \\
\text { than } 2 \text { years. Some people might only live for half } \\
\text { a year. But others will live much longer, maybe as } \\
\text { much as } 4 \text { years. }\end{array}$ \\
\hline & $\begin{array}{l}\text { Patient: Yes, I understand that. So, you can't predict } \\
\text { which group I belong to? }\end{array}$ \\
\hline & Oncologist: No. \\
\hline \multirow[t]{6}{*}{ Explicit low } & Patient: Well, how long have I got? \\
\hline & Oncologist: Your life expectancy? \\
\hline & $\begin{array}{l}\text { Patient: Yes, as a rough idea. Do you know that in } \\
\text { general terms? }\end{array}$ \\
\hline & $\begin{array}{l}\text { Oncologist: That's very difficult to predict, because it } \\
\text { can differ from person to person. You do have a } \\
\text { very serious disease, which will limit your life } \\
\text { expectancy. That is the only thing we can say for } \\
\text { sure. There are women who live for quite a long } \\
\text { time with the type of breast cancer you have, and } \\
\text { there are women who live less long. The } \\
\text { comments you often see on television or read in } \\
\text { magazines, about "you only have so long to live" } \\
\text { aren't realistic, because we do not know that in } \\
\text { any individual case.... So, no, I don't know how } \\
\text { it will be for you. }\end{array}$ \\
\hline & $\begin{array}{l}\text { Patient: Yes, I understand that. That's something } \\
\text { you can't predict. }\end{array}$ \\
\hline & Oncologist: No. \\
\hline \multirow[t]{3}{*}{ Reassurance high } & $\begin{array}{l}\text { 1. Oncologist: But whatever action we do take, and } \\
\text { however that develops, we will continue to take } \\
\text { good care of you. We will be with you all the } \\
\text { way. }\end{array}$ \\
\hline & $\begin{array}{l}\text { 2. Oncologist: We will do and will continue to do our } \\
\text { very best for you. }\end{array}$ \\
\hline & $\begin{array}{l}\text { 3. Oncologist: And whatever happens, we will never } \\
\text { abandon you. You are not facing this on your } \\
\text { own. }\end{array}$ \\
\hline Reassurance low & No fragments were added. \\
\hline
\end{tabular}




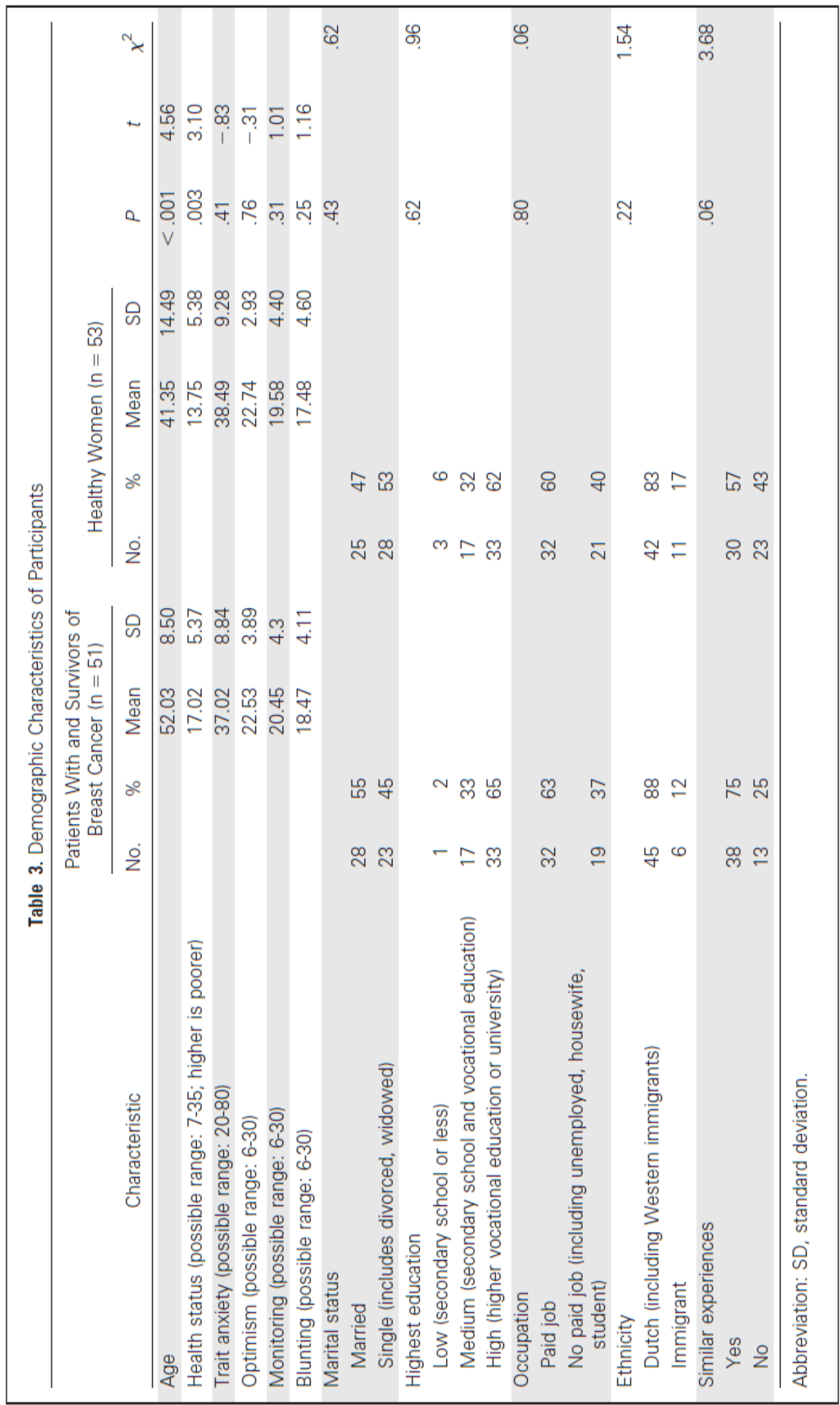


Vliet, L.M. van, Wall, E. van der, Plum, N.M., Bensing, J.M. Explicit prognostic information and 7 reassurance about nonabandonment when entering palliative breast cancer care: findings from 1 a scripted video-vignette study. Journal of Clinical Oncology: 2013, 31(26), 3242-3249

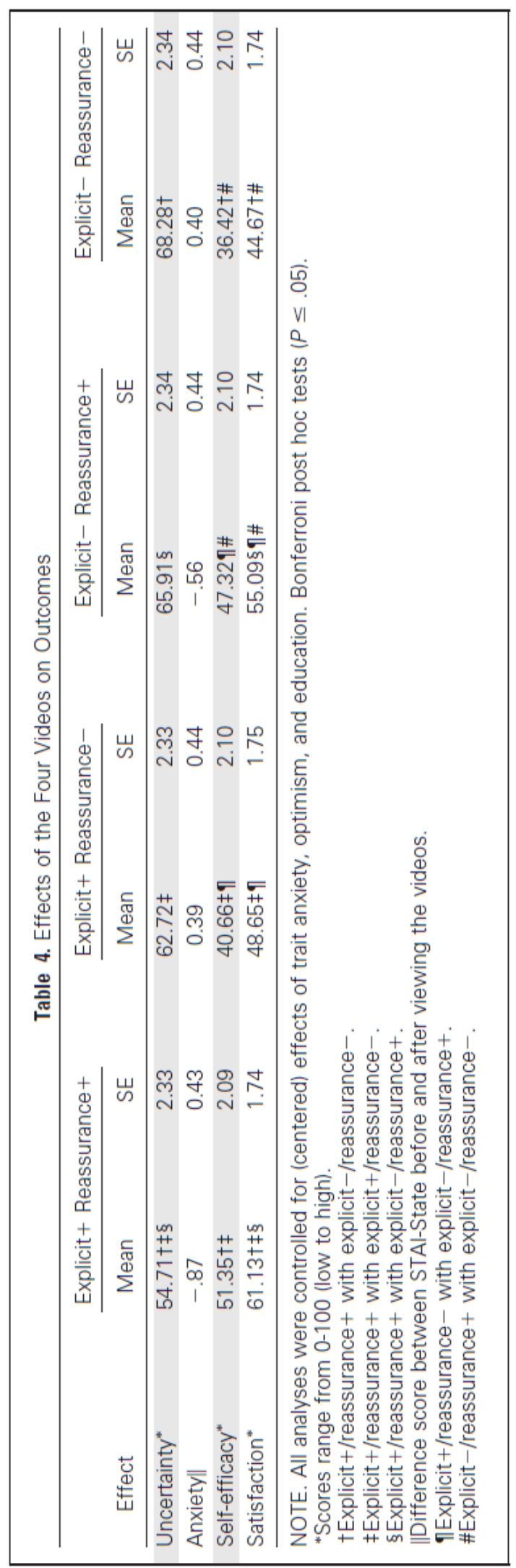


Vliet, L.M. van, Wall, E. van der, Plum, N.M., Bensing, J.M. Explicit prognostic information andreassurance about nonabandonment when entering palliative breast cancer care: findings from a scripted video-vignette study. Journal of Clinical Oncology: 2013, 31(26), 3242-3249

Table 5. Main Effects of Explicitness and Reassurance on Outcomes

\begin{tabular}{lrrrrrrrr}
\hline & \multicolumn{4}{c}{ Explicitness } & & \multicolumn{4}{c}{ Reassurance } \\
\cline { 2 - 5 } \cline { 7 - 9 } \multicolumn{1}{c}{ Effect } & Beta & $95 \% \mathrm{Cl}$ & $P$ & & Beta & $95 \% \mathrm{Cl}$ & $P$ \\
\hline Uncertainty & -.36 & -.50 to -.21 & $<.001$ & & -.23 & -.38 to -.08 & .002 \\
Anxiety & -.04 & -.17 to 0.09 & .562 & -.22 & -.35 to -.09 & .001 \\
Self-efficacy & .20 & 0.06 to 0.33 & .004 & & .47 & 0.34 to 0.61 & $<.001$ \\
Satisfaction & .28 & 0.16 to 0.40 & $<.001$ & & .61 & 0.48 to 0.73 & $<.001$ \\
\hline
\end{tabular}

NOTE. All analyses were controlled for (centered) effects of trait anxiety, optimism, and education. All analyses were performed using z scores. 
Vliet, L.M. van, Wall, E. van der, Plum, N.M., Bensing, J.M. Explicit prognostic information andreassurance about nonabandonment when entering palliative breast cancer care: findings from 1 a scripted video-vignette study. Journal of Clinical Oncology: 2013, 31(26), 3242-3249

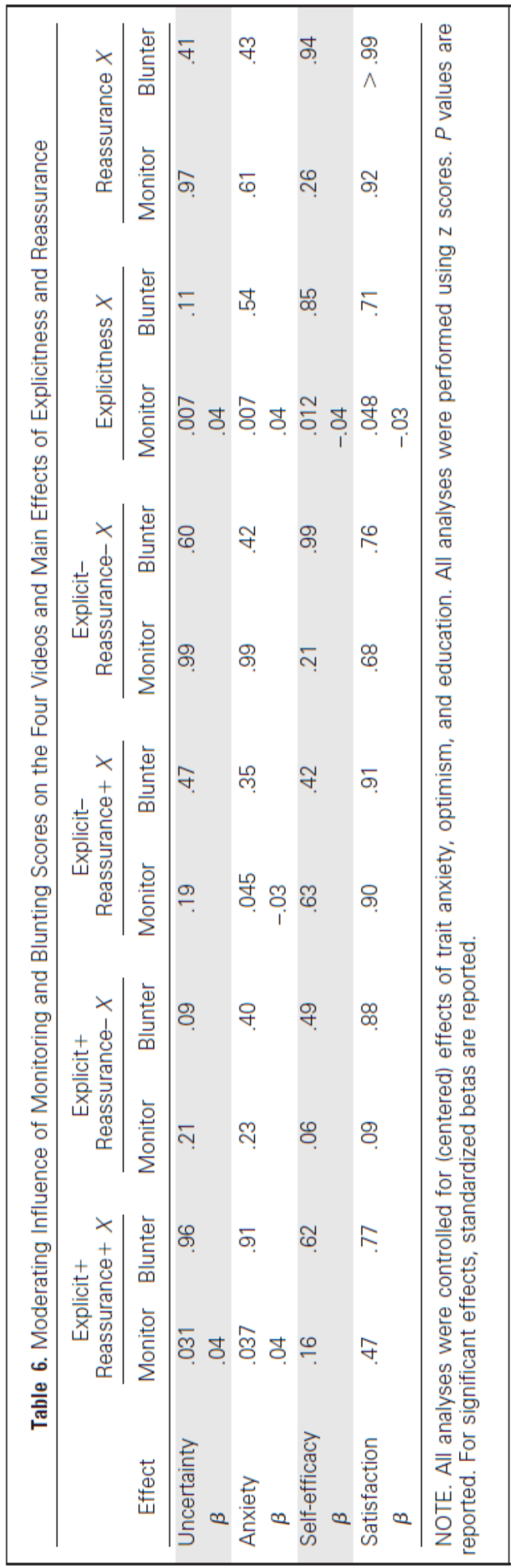


Vliet, L.M. van, Wall, E. van der, Plum, N.M., Bensing, J.M. Explicit prognostic information and reassurance about nonabandonment when entering palliative breast cancer care: findings from 1 a scripted video-vignette study. Journal of Clinical Oncology: 2013, 31(26), 3242-3249

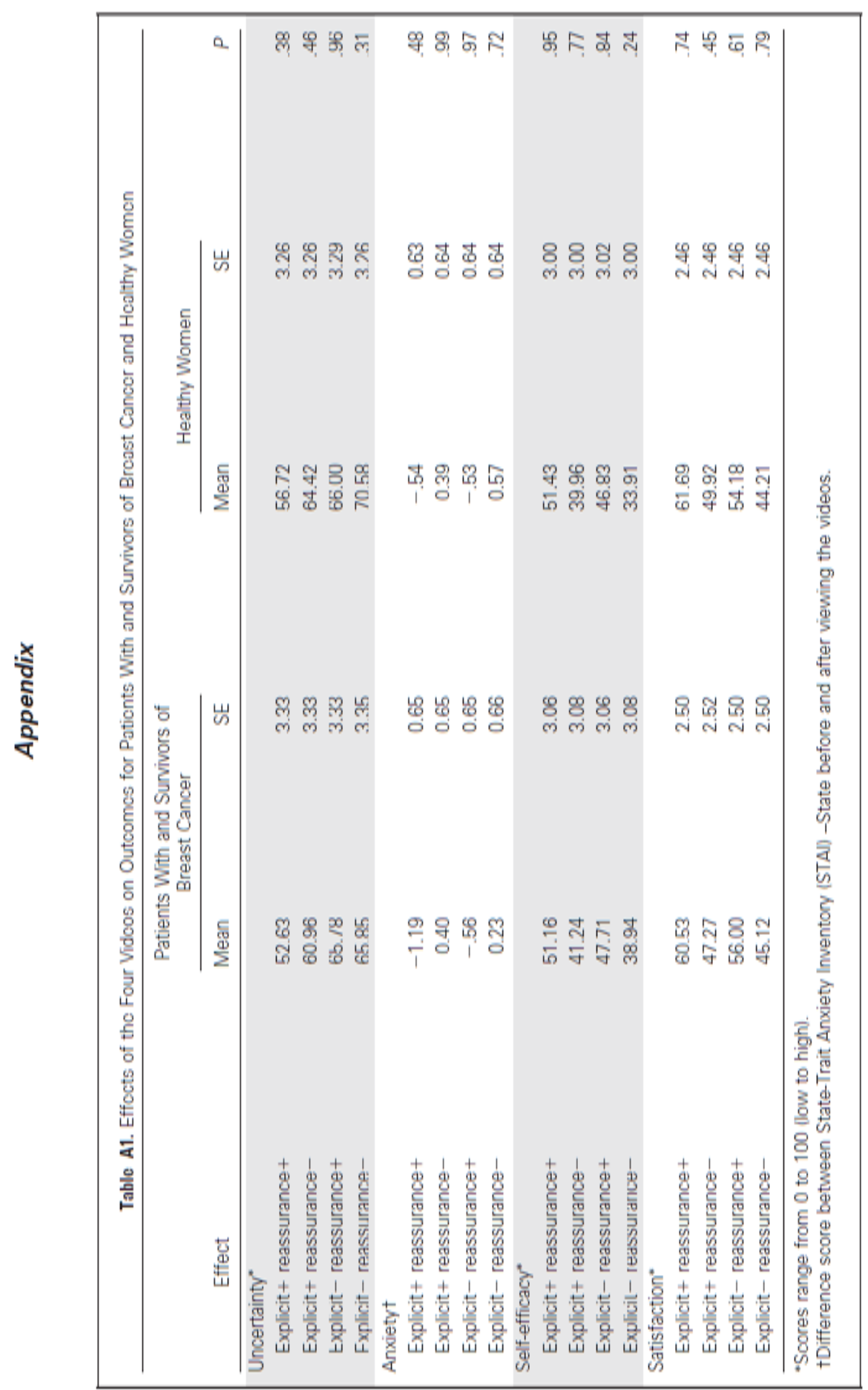

